\title{
Automatic phonological priming in visual word recognition
}

\author{
GLYN W. HUMPHREYS \\ Birkbeck College, University of London, London WCIE 7HX, England \\ LINDSAY J. EVETT \\ MRC Applied Psychology Unit, Cambridge CB2 2EF, England \\ and \\ DAVID E. TAYLOR \\ University of Bristol, Bristol BS8 1HH, England
}

\begin{abstract}
Theories of visual word recognition have proposed that a word's phonological properties can be involved in reading visually presented words. Further, it is commonly supposed that this phonological information can be arrived at in at least two ways: (1) by looking it up after identifying the word visually (a lexical route) or (2) by rule-governed translating of the word's orthographic code (a nonlexical route). Four experiments were conducted to examine whether phonological information is automatically accessed in visual word recognition, and, if so, how this occurs. A priming technique was used with a display sequence of mask, prime, target, mask. Subjects were asked to make written responses to any words that they thought were present, and prime identification was minimal. A facilitatory effect of phonological priming on target identification occurred when primes were homophones of targets. However, no similar facilitation occurred when the prime was a nonword homophone of the target. Further, the homophone priming effect was found irrespective of whether targets followed the spelling-to-sound rules of English. The results suggest that automatic access to phonology can occur in visual word recognition and that it operates by means of a lexical route.
\end{abstract}

Current models of word recognition assume that the phonological properties of a visually presented word can be arrived at in at least two ways (e.g., Coltheart, 1978, 1980; Forster, 1976; Meyer, Schvaneveldt, \& Ruddy, 1974; Morton \& Patterson, 1980). One way is by looking up stored phonology after identifying the word visually (a lexical route); the other is by rule-governed translating of the word's orthographic code (a nonlexical route). The present paper asks whether one or both of these routes operate automatically (i.e., without intention) in visual word processing. The first part of the paper (Experiments 1 and 2) investigates whether phonological information can be automatically accessed. The mechanisms of such automatic access are dealt with in the second section (Experiments 3 and 4).

One study concerned with the automatic access of phonological information in visual word recognition was

David Taylor is now at the Department of Psychology, University of Newcastle upon Tyne, Claremont Place, Newcastle upon Tyne, NE1 7RU, England. The authors would like to thank Clive Frankish, Mike Harris, and Penny Wilcox for assistance with computing, and Pippa Lopez for typing the manuscript. We would also like to thank Max Coltheart and two anonymous referees for comments. Address reprint requests to Lindsay Evett, MRC Applied Psychology Unit, 15 Chaucer Road, Cambridge CB2 2EF, England. reported by Hillinger (1980, Experiment 3). He used a priming technique in which subjects made a lexical decision about visual prime- and target-letter strings. In a test that assessed whether phonological information is automatically accessed, performance when targets were primed by phonologically similar but graphemically different words (e.g., EIGHT-MATE) was compared with performance when primes were neutral (e.g., ******-MATE). Hillinger found that, relative to the neutral-prime baseline, lexical decisions were facilitated by phonological priming. This indicates that phonological information from the prime affected target recognition.

There are at least two ways in which such a facilitatory priming effect could occur. One is by the prime automatically activating representations common to both stimuli. The other is by subjects using phonological information from the prime to anticipate the target (Posner, 1978; Posner \& Snyder, 1975). Such an anticipatory strategy would lead to incorrect expectations when primes and targets are unrelated, precipitating an inhibition effect relative to the neutral condition (McLean \& Shulman, 1978; Neely, 1977). Since, in Hillinger's (1980) study, no inhibition effect was found when primes and targets were phonologically unrelated (e.g., VEIL-MATE), it appears that subjects did not anticipate targets from the phonological properties of primes. 
This suggests that priming occurred because phonological information was automatically extracted from primes, and this facilitated the recognition of subsequent phonologically related targets.

However, there is a problem with this conclusion since phonological coding may only have been undertaken because of the nature of the nonwords used. Subjects in Hillinger's (1980) study had to discriminate between orthographically regular, pronounceable nonwords (e.g., TANE) and words to make correct lexical decisions about both primes and targets. Under these circumstances, phonological coding may occur because of the strategy used by subjects to facilitate lexical decision; changing the nature of the nonwords can minimize the occurrence of such coding (see Shulman, Hornak, \& Sanders, 1978). Further, any strategically produced phonological code may take some measurable amount of time to decay. Thus, even if subjects do not anticipate targets on the basis of such information from primes, it will influence ("automatically") the processing of targets presented in close temporal succession.

To ensure that priming reflects only that information that is unintentionally accessed in word recognition, there must be stricter control over the strategic processing of primes and targets. A study that goes some way toward this was reported by Tanenhaus, Flanigan, and Seidenberg (1980). They used a Stroop color-naming task, in which colored target words were preceded by phonologically similar or dissimilar word primes. Colornaming latencies to targets were slower when primes were phonologically similar (TOWEL-HOWL) than when they were dissimilar (BEND-HOWL). Since anticipating targets from primes disrupts color naming, it seems likely that this effect reflects the information automatically accessed by primes (however, see Logan, 1980).

Unfortunately, a further problem exists for this study. Tanenhaus et al. (1980) failed to incorporate a graphemic control condition, in which phonologically different primes and targets matched the letters in common between phonologically similar stimuli. Without this control, it is impossible to tell whether the priming effect was graphemic rather than phonological in origin (cf. Evett \& Humphreys, 1981; Rayner, 1979).

To examine the information automatically accessed by primes, we need to prevent the intentional use of prime information by subjects and to carefully control for all the attributes of the stimuli that could produce priming effects. These were the aims of Experiments 1 and 2 here.

One way to prevent the intentional usage of prime information is to present primes under conditions that minimize their explicit identification but that nevertheless allow priming to occur. Such conditions have recently been demonstrated by Allport (1977), Evett and Humphreys (1981), Fowler, Wolford, Slade, and Tassinary (1981), and Marcel (in press). These studies have shown that semantic priming effects can occur when primes are backward-pattern masked so that they cannot be identified.

Evett and Humphreys (1981) tested for phonological priming under such conditions. They used a fourfield masking procedure in which the presentation of the prime and target stimuli was preceded and followed by the presentation of a pattern mask. Although subjects were required to identify any words present, there was minimal identification of primes. This shows that subjects could not use prime information intentionally, and, therefore, that any priming effects were occurring automatically (Posner, 1978). Tests for phonological priming effects were made in the following manner: In a phonological experimental condition, primes and targets were phonologically and graphemically similar (e.g., bribe-TRIBE, hence-FENCE). In a graphemic experimental condition, the stimuli were graphemically similar but phonologically different (break-FREAK, couchTOUCH). Each of these conditions was paired with an unrelated word-pair control, in which pair members were interchanged within each condition (fence-BRIBE, tribeHENCE, or tough-BREAK, freak-COUCH). Evett and Humphreys argued that phonological priming would be demonstrated by increased facilitation of target recognition in the phonological experimental condition relative to the graphemic experimental condition, assessed against the appropriate baseline controls (cf. Meyer et al., 1974; Shulman et al., 1978). However, they found that target recognition was facilitated in both experimental conditions, and crucially, there was no increment due to phonological similarity.

There are three possible reasons why a phonological priming effect was not found by Evett and Humphreys (1981). One is that phonological coding of visual words is an optional strategy and does not occur when words cannot be intentionally processed (Carr, Davidson, \& Hawkins, 1978; Davelaar, Coltheart, Besner, \& Jonasson, 1978; Hawkins, Reicher, Rogers, \& Peterson, 1976). The second reason is that access to phonological information takes longer than access to orthographic information and, thus, phonological coding is more disrupted by masking (Coltheart, 1978, 1980; Meyer \& Gutschera, Note 2). The third reason is that the phonological similarity of primes and targets was simply not sufficient to produce an automatic priming effect. For instance, in the phonological experimental condition, the first phoneme of primes and targets differed. This would prevent phonological priming dependent on a complete overlap between the phonological representations of the stimuli. $^{1}$

The present study tested the last proposal. The priming technique developed by Evett and Humphreys (1981) was used to investigate automatic priming between homophonically related stimuli (i.e., stimuli with identical phonological representations). Experiments 1 and 2 establish a homophone priming effect between word pairs, independent of their graphemic 
similarity. These experiments demonstrate that phonological information is automatically accessed in visual word recognition. Experiments 3 and 4 examine how such access operates. In particular, they examine whether automatic access is via a lexical or a nonlexical route.

\section{EXPERIMENT 1}

This experiment tested whether a phonological priming effect could be found between homophonic word pairs over and above any effects due to their graphemic similarity. Accordingly, there were two main conditions. In the homophone condition, targets were primed by phonologically identical words (e.g., sale-SAIL). In a graphemic control condition, targets were primed by phonologically unrelated words, chosen so that letters in the same position in these words and targets matched the letters in the same position in homophonic word pairs (salt-SAIL). If phonological priming occurs, target recognition should benefit in the homophone condition relative to the graphemic control condition.

In addition to these conditions, there were two baseline treatments. In one condition, primes and targets had the same identity. In this condition, maximum priming should occur (Evett \& Humphreys, 1981), and it is the limiting case for facilitatory priming effects. In the second baseline treatment, primes and targets were graphemically and phonologically unrelated words (as far as possible, there were no letters in the same position in the stimuli in this condition). The effectiveness of priming will be measured relative to this treatment.

\section{Method}

Unless otherwise stated, the same method was used in Experiments 14 .

Subjects. The 28 subjects, 16 females and 12 males, were all paid members of the Birkbeck College subject pool. Subjects were run individually in one session lasting about $30 \mathrm{~min}$, and all had normal or corrected-to-normal vision.

Materials and Design. A pool of 72 target words was selected, with word frequencies ranging between 1 and 3,562 per million (Kučera \& Francis, 1967). The mean target frequency was 171 per million. Target words were divided into four groups of 18 , balanced for word length and frequency, and primes and targets were balanced for the relative dominance of the homophone pairs. A complete list of all the stimuli used in all the experiments is presented in the appendices.

There were four treatments (same identity, homophone, graphemic control, and unrelated control), defined by the type of prime paired with the target. Target words were presented in each treatment by combining the four sets of words with four groups of subjects, using a Latin square design. No subjects saw the same target twice. The order of the trials for each subject was randomized using the computer.

The words were between four and six letters long, and the relative lengths of primes and targets were matched in the four conditions. All words were centered around a central fixation point that appeared directly underneath the words. Targets were always in uppercase and primes in lowercase. This prevented any differential contour summation-contrast reduction effects in the same identity condition. Characters subtended a visual angle of approximately $5 \mathrm{deg}$ horizontally by $1.0 \mathrm{deg}$ vertically. The largest six-character words were approximately $3.0 \mathrm{deg}$ of visual angle wide. The mask covered the same spatial region as the words and was about 2.0 deg high by $3.0 \mathrm{deg}$ wide. It was generated from randomly oriented fragments from both upper- and lowercase letters.

Stimulus presentation, timing, and data collection were controlled by a PDP-11/10 computer. Stimuli were plotted on an Advance Instruments oscilloscope (Model 05 250), using a P-31 rapid decay phosphor. This had the characteristic of dropping to $1 \%$ maximum brightness in $.25 \mathrm{msec}$ on the removal of a character.

Procedure. A four-field masking paradigm was used. The presentation sequence was mask, prime, target, mask. There were no interstimulus intervals. Subjects were told that they would be presented with pairs of pattern masked words, and they were asked to identify any words they thought had been present in the display. They were asked to guess if unsure, and responses were required on all trials. Previous work shows that reliable priming effects can be achieved using this procedure without subjects being able to identify primes (Evett \& Humphreys, 1981).

Subjects were instructed to fixate the central point on the oscilloscope. When fixated, the display was immediately initiated by the experimenter depressing a key. Written responses were made, and subjects were asked to write their responses in the case in which they thought the words were presented.

Prior to the experimental trials, a series of threshold trials were conducted to determine the duration at which a subject would perform at approximately $40 \%$ correct target identification in the unrelated control condition. Thresholds were found using the descending method of limits, and only unrelated primes and targets were used. Blocks of eight trials were presented, starting with field durations at which targets were relatively easy to identify, and then decreasing exposure times (over the blocks) until the required level of performance was maintained over 32 trials. The durations of the four fields were always kept equal during this procedure. Following the threshold trials, experimental trials were carried out using the exposure durations established for each subject.

On completing the experimental trials, subjects were requested to comment on the task. They were asked whether they had been conscious of two words in the displays and whether they had seen stimuli in either upper- or lowercase. Finally, they were informed about the nature of the experiment.

\section{Results and Discussion}

The mean field duration established during the threshold procedure was $35 \mathrm{msec}$, and there was a range between 25 and $50 \mathrm{msec}$ over subjects. The mean percent correct target identifications in each condition are given in Table 1.

These data were analyzed using a mixed-design analysis of variance with one within-subjects factor (conditions) and one between-subjects factor (subject groups). ${ }^{2}$

Table 1

Mean Percentage Correct Target Identification per Condition in Experiment 1

\begin{tabular}{llc} 
Condition & & $\begin{array}{c}\text { Percentage } \\
\text { Correct }\end{array}$ \\
\hline Same Identity & made-MADE & 65.57 \\
Homophone & maid-MADE & 56.28 \\
Graphemic Control & mark-MADE & 47.39 \\
Unrelated Control & ship-MADE & 43.25 \\
\hline
\end{tabular}


There was a statistically significant conditions effect $[F(3,72)=30.97, p<.001]$ but no difference between the subject groups $[F(3,24)=2.97, p>.05]$. The Groups by Conditions interaction was also nonsignificant $[F(9,72)=1.99, p>.05]$.

The main conditions effect was further analyzed using the Newman-Keuls method. Relative to the graphemic and unrelated control conditions, target recognition was facilitated in both the same identity and the homophonic conditions ( $p<.01$ for all comparisons). Performance benefitted most in the same identity condition $(\mathrm{p}<.01$ for the same identity vs. the homophone condition). There was no difference between the graphemic and the unrelated control condition.

The difference between the homophone and the graphemic control condition indicates that a reliable phonological priming effect occurred. The facilitation from phonological priming alone, though, was not as great as in the same identity condition, when primes and targets had the same graphemic, phonological, and semantic properties. These results replicate unpublished experiments by Taylor (1981). He used a slightly different procedure in which primes and targets were presented simultaneously, one above and one below fixation. Both stimuli were backward-pattern masked, and subjects were instructed to identify the target word (see also Allport, 1977). Again, a minimum of primes was reported when phonological priming effects occurred. The reliability of the effects over the different procedures indicates their robustness.

Relative to the unrelated control condition, there was no statistically significant effect of priming in the graphemic control condition. The graphemic control condition was included in this experiment to assess the effects of graphemic similarity between primes and targets in the homophone condition. This was necessary because large graphemic priming effects are found using the present technique when there is a sufficient level of graphemic similarity between primes and targets (e.g., Evett \& Humphreys, 1981, Experiments 2 and 3, in which there were approximately $74 \%$ shared letters in the same position in primes and targets, compared with 42.7\% in Experiment 1 here). Since the matched graphemic control condition did not result in a significant priming effect, it is clear that graphemic information was not responsible for the priming effect observed in the homophone condition. Nevertheless, there was some effect of graphemic similarity between primes and targets on target identification. This was shown by a reliable correlation between the number of letters that were shared between prime-target pairs in the same position within the word and the size of the difference in target identification performance between the graphemic control and the unrelated control conditions (Pearson product-moment coefficient; $r=.546, p<.01$ ). Phonological priming in the homophone condition operated over and above any effects due to graphemic similarity between primes and targets.
Five subjects reported that they thought there was more than one word in the displays on some occasions. ${ }^{3}$ However, when two responses were made, one was usually the target or a response preserving a majority of target letters, and the other was usually quite different from either the prime or the target on the trial. This latter type of response was often made consistently across a range of primes and targets and probably reflects the identification of letter fragments in the mask. Only one subject reported seeing any lowercase stimuli. This subject correctly reported three lowercase primes in the homophone condition. However, in all other respects his data matched those of the other subjects. Omitting his data made no difference to the results.

Pooling over subjects, there were eight $(1.6 \%)$ correct prime identifications in the homophone condition, five $(1.0 \%)$ in the graphemic control condition, and zero in the unrelated control condition. The slightly higher numbers of prime reports in the homophone and graphemic control conditions, relative to the unrelated control, can probably best be attributed to the transposition of letters from primes to target responses (see Evett \& Humphreys, 1981) or to guesses generated from the identification of some target letters. On both counts, there would be a higher probability of reporting primes when primes and targets have some letters in common (in the homophone and graphemic control conditions) than when the stimuli are unrelated. Nevertheless, even in the homophone and graphemic control conditions, prime identifications were minimal. It is reasonable to conclude that primes were not intentionally used.

The reason why prime identification is so markedly poorer than target identification in the present paradigm is not clear. One possibility is that prime words are backward masked more strongly by target words than target words are by the pattern mask (Johnston \& McClelland, 1980; Taylor \& Chabot, 1978). Primes are probably subject to forward masking by random pattern, too. A second possibility is that target information may simply be stronger than prime information since there is less temporal delay before its report. However, it is also possible that four-field masking operates quite differently to the more usual two-field masking function (e.g., Michaels \& Turvey, 1979; Turvey, 1978). More definite conclusions concerning four-field masking and the relation between this and other forms of masking must await further research. Nevertheless, masked primes did access phonology. It seems from this that masking can prevent the retrieval of stimulus information rather than stimulus processing (Humphreys, 1981; Marcel, in press). For instance, masking could disrupt the visual code of the stimulus that is integrated with other forms of information after lexical access (Allport, 1977).

The principal finding of this experiment is that, providing the phonological representations of primes and targets are identical, phonological priming can 
occur using an automatic priming procedure that minimizes prime identification. It appears from this that primes automatically access phonological information and that this information can facilitate target identification.

Unfortunately, a possible objection to this conclusion can be made, based on the adequacy of the graphemic control condition. In this condition, prime words were selected so that the letters they contained in the same position as targets matched the letters in the same position between homophonic stimuli. However, the condition did not control for any effects due to common letters in different positions in the homophonic word pairs. There were 44 instances in which homophone word pairs contained an extra diffferent-position common letter than the equivalent graphemic control word pairs (e.g., bear-BARE vs. bean-BARE). There were only eight instances in which graphemic control word pairs had an extra different-position common letter than the matching homophones (e.g., veal-VALE vs. veilVALE). It is possible that extra cross-position priming produced the facilitation in the homophone condition relative to the graphemic control. Experiment 2 tested this proposal.

\section{EXPERIMENT 2}

In this experiment, a new graphemic control condition was constructed to match any effects due to different-position common letters in homophonic word pairs. In this new condition, target words were primed by nonwords chosen so that they contained all the letters in common with targets that were in common between primes and targets in the homophone condition (e.g., peace-PIECE vs. perce-PIECE). Word primes could not be used in this condition because a large enough sample could not be generated. However, it is important to realize that graphemic priming between nonword primes and word targets is as large as that between word primes and targets in the present paradigm (Evett \& Humphreys, 1981). No differences should be introduced simply because nonwords rather than words were used in the graphemic control condition. Similar to Experiment 1 , in Experiment 2 there were two baseline conditions in which word primes and targets either had the same identity or were graphemically and phonologically unrelated.

\section{Method}

The 16 subjects, 11 females and 5 males, were all paid members of the Birkbeck College subject pool. None of the subjects had taken part in Experiment 1. All had normal or corrected-tonormal vision.

There were 72 target words between four and six letters long, with word frequencies between 0 and 750 per million in the Kučera and Francis (1967) norms. The mean word frequency of targets was 51 per million. There were four treatments (same identity, homophone, graphemic control, and unrelated control), manipulated within subjects. Targets were divided into four groups of 18 , balanced for word length and frequency. These were then balanced over the treatments by combination with four groups of subjects using a Latin square design.

Each subject received 72 experimental trials, with the order of presentation of the treatments randomized by computer. Subjects were asked to identify any words they thought were presented, and they made written responses. Exposure durations for the experimental trials were individually determined by a series of threshold trials during which unrelated word primes were used.

\section{Results and Discussion}

The mean field duration over subjects was $40 \mathrm{msec}$, and a range between 30 and $55 \mathrm{msec}$ was required.

The mean percent correct target identifications as a function of the conditions are shown in Table 2. These results were submitted to a mixed-design analysis of variance with one between-subjects factor (groups) and one within-subjects factor (conditions). There was no difference between the groups $(F<1.0)$. However, there was a reliable difference between the conditions $[F(3,36)=13.62, p<.001]$. The Group by Conditions interaction was not significant $[F(9,36)=1.54, p>.05]$.

A Newman-Keuls analysis of the conditions effect revealed that, relative to the graphemic and unrelated control treatments, performance was facilitated both by same identity and by homophone priming (all $\mathrm{p}<.01$ ). Target recognition was also better in the same identity condition than in the homophone condition $(p<.05)$. There was no difference between the graphemic and the unrelated control conditions. Nevertheless, as in Experiment 1, there was a reliable correlation between the size of the graphemic priming effect in the graphemic control condition and the number of shared letters between primes and targets in the same letter position (Pearson product-moment coefficient; $\mathrm{r}=.45, \mathrm{p}<.01$ ). This again shows that although graphemic similarity affects performance, it is not responsible for facilitating target identification in the homophone condition.

Pooled over subjects, out of 288 trials in each condition, there were six $(2.1 \%)$ correct prime identifications in the homophone condition and one $(.3 \%)$ correct prime identification in the unrelated control. On none of the trials when primes were identified were targets also identified. As in Experiment 1, prime identification was minimal. It again seems likely that more reports were made in the homophone than the unrelated condition because of letter transpositions from primes to target

Table 2

Mean Percentage Correct Target Identification per Condition in Experiment 2

\begin{tabular}{llc}
\hline \multicolumn{1}{c}{ Condition } & & $\begin{array}{c}\text { Percentage } \\
\text { Correct }\end{array}$ \\
\hline Same Identity & hair-HAIR & 66.68 \\
Homophone & hare-HAIR & 58.33 \\
Graphemic Control & harn-HAIR & 47.23 \\
Unrelated Control & food-HAIR & 45.50 \\
\hline
\end{tabular}


responses or because of guesses from the identification of some target letters. No subjects reported the presence of lowercase stimuli.

These results essentially replicate the findings of Experiment 1. Thus, a homophone priming effect occurred, even though primes could not be explicitly identified and even when there was strict control over all the common letters between homophonic word pairs.

Taken together, Experiments 1 and 2 demonstrate that primes automatically access phonological information and that this information facilitates target recognition. Importantly, access to phonology is not limited by masking conditions or by the processing of the words being unintentional. The question of the means by which the facilitation effect occurred is examined in Experiments 3 and 4.

\section{EXPERIMENT 3}

As mentioned earlier, it is often assumed that there are two ways in which the phonological representation of a visual word can be accessed (e.g., Coltheart, 1978, 1980; Morton \& Patterson, 1980). One way is via a lexical route. A word first activates its orthographic representation in the lexicon, and then may contact its corresponding phonological representation either directly or after deriving its meaning from its semantic representation. The other way is via a nonlexical route. Probably the most detailed exposition of this route has been given by Coltheart (1978). He proposes that lexical access can be obtained phonologically by a rule-based process termed grapheme-phoneme conversion (GPC). GPC operates on the basis of the spelling-to-sound rules of English (Venezky, 1970) at the level of single graphemes or, at most, digraphs. GPC proceeds irrespective of the lexical status of the letter string but, because of the irregularity of English, it will only produce the correct pronunciation for a majority of letter strings (regular letter strings). This view neatly accounts for why words that do not conform to the rules (exception words) are pronounced more slowly than regular words (Baron \& Strawson, 1976; Gough \& Cosky, 1977; Stanovich \& Bauer, 1978). Exception words can only be correctly pronounced by use of the lexical route, whereas regular words can be correctly pronounced using either this or the nonlexical route. Thus, regular words can be pronounced faster either because there is an overlap in the distribution times for the two routes or because there is no conflicting phonological information generated in their processing.

Experiment 3 examined whether or not such a nonlexical route was involved in the phonological priming effects of Experiments 1 and 2. There were again two main conditions. In the pseudohomophone condition, primes were nonwords that were phonologically identical to target words (e.g.. smorl-SMALL). In a graphemic control condition, primes were nonwords that were phonologically different to targets but bore the same graphemic relationship to them as the pseudohomophones. Thus, their letters in common in the the same position as targets were the same as the pseudohomophone primes (e.g., smoul-SMALL). Matching for letter correspondence across position was neglected since Experiment 2 showed that any cross-position graphemic priming was minimal.

If phonological information is automatically activated via a nonlexical route, a pseudohomophone priming effect should occur. That is, target recognition should be better in the pseudohomophone condition than in the graphemic control condition. Alternatively, if only the lexical route is involved, there should be no difference between these two conditions.

The same identity and the graphemically and phonologically unrelated prime-target conditions were again included as the baselines for priming. However, primes in the unrelated condition were nonwords to ensure that any differences between this condition and the experimental conditions were not due to the lexical status of primes.

\section{Method}

There were 28 subjects, 18 male and 10 female. Of these, 20 were paid members of the Birkbeck College subject pool, and 8 were either volunteer postgraduates or undergraduates from Bristol University. All participants served in a single experimental session lasting about $40 \mathrm{~min}$, and all had normal or corrected-to-normal vision.

A set of 80 target words was generated. Targets were between four and six letters long and had word frequencies ranging from 1 to 542 words/million (Kucera \& Francis, 1967). The mean frequency was 84 words/million. The four prime-target treatments (same identity, pseudohomophone, graphemic control, unrelated control) were varied within subjects. Targets were separated into four groups of 20 , matched for word length and frequency. These words were combined with four groups of seven subjects using a Latin square design to balance targets over conditions.

Prior to the experimental trials being administered, exposure durations appropriate to produce about $40 \%$ correct target identification in the unrelated nonword control condition were found for each subject using the threshold procedure.

The eight subjects run at Bristol University saw displays plotted on a Tektronix 602 oscilloscope, equipped with a P-31 rapid decay phosphor. These subjects entered their responses on a Decscope keyboard. They were asked to type in a response ordinarily if they thought the stimulus was in uppercase and to place a "hash" symbol (\#) in front of their response if they thought the stimulus was in lowercase.

Subjects were told that displays could contain two words or a word and a nonword. They were told that nonwords would be orthographically regular and pronounceable.

\section{Results and Discussion}

The mean field duration was $35 \mathrm{msec}$, and there was a range between 25 and $50 \mathrm{msec}$ over subjects. Inspection of the data indicated no marked differences between the results collected from Birkbeck College and those from Bristol University. The data were therefore collapsed together and means taken over subject groups. Table 3 shows the overall mean percent correct target identification in the conditions. 
Table 3

Mean Percent Correct Target Identification per Condition in Experiment 3

\begin{tabular}{llc}
\hline Condition & & $\begin{array}{c}\text { Percentage } \\
\text { Correct }\end{array}$ \\
\hline Same Identity & small-SMALL & 63.18 \\
Pseudohomophone & smorl-SMALL & 49.93 \\
Graphemic Control & smoul-SMALL & 48.54 \\
Unrelated Control & thoke-SMALL & 41.82 \\
\hline
\end{tabular}

A mixed-design analysis of variance was carried out, with one between-subjects factor (groups) and one within-subjects factor (conditions). There was a significant main effect of conditions $[F(3,72)=15.43$, $p<.001]$. However, neither the groups main effect nor the Groups by Conditions interaction was significant $[F(3,24)=1.52$ and $F(9,72)=1.65$, respectively; ps $>.05]$.

The conditions effect was further analyzed using the Newman-Keuls method. There was an overall facilitation effect for the same identity condition over the other conditions ( $p<.01$ for all comparisons) and a marginal effect for the pseudohomophone and graphemic control conditions relative to the unrelated control (both ps $<.05$ ). Critically, there was no difference between the pseudohomophone and the graphemic control conditions.

No correct prime identifications were made. Generally, subjects found it even more difficult to report a word and a nonword in this study than to report two words in the earlier studies. Only five subjects ever made two responses on one trial, and on only three occasions was a nonword reported. None of the responses contained a majority of prime letters; one contained a majority of target letters and the other two were unrelated to either the prime or the target on the given trials. No subjects reported seeing any lowercase letters. From this it appears that primes were not intentionally processed and, thus, that automatic priming occurred.

The most important result of this experiment is that there was no reliable phonological priming effect in the pseudohomophone condition. Although there was a small trend in this direction (see Table 3), only 12 of 28 subjects showed any facilitation for the pseudohomophone condition over the graphemic control. This contrasts with the consistent facilitation effects of $8.89 \%$ and $11.1 \%$ increased target recognition from homophone priming in Experiments 1 and 2. These results suggest that primes here do not automatically access their phonological representations via a nonlexical route and, by way of elimination, that the lexical route mediated the earlier homophone priming effects.

In this experiment, the trend for facilitated target identification in the graphemic control relative to the unrelated control condition attained statistical significance. There were similar trends in the data of Experiments 1 and 2 , although they were not statistically significant. The size of the facilitation effect here is not much greater than in the earlier experiments $(6.72 \%$ in
Experiment 3 vs. $4.14 \%$ and $1.73 \%$ in Experiments 1 and 2 , respectively) and probably reflects the slightly larger difference in the graphemic similarity of prime-target pairs in the two control conditions of Experiment 3, compared with the earlier studies. ${ }^{4}$ Nevertheless, graphemic similarity was correlated with performance in Experiments 1 and 2, when homophone priming also occurred. This indicates that the reliable graphemic priming effect found in Experiment 3 cannot account for the absence of phonological priming in the pseudohomophone condition. This conclusion is further supported by the results of Experiment 4, in which reliable main effects of both graphemic and phonological priming are found.

Unfortunately, there are other problems in interpreting the results of Experiment 3 as evidence for automatic lexical access to phonology. One problem is that the pseudohomophones may not have been phonologically identical to their matched targets. Against this, subjects did take longer to reject these nonwords than matched nonwords that were phonologically different from words in a lexical decision task. This shows that the pseudohomophones were adequate in this respect (cf. Coltheart, Jonasson, Davelaar, \& Besner, 1977; Rubenstein, Lewis, \& Rubenstein, 1971). ${ }^{5}$ However, there are further possibilities. For instance, the pseudohomophones might have conformed less to GPC rules than the homophone primes used in Experiments 1 and 2. Such problems will remain where interpretation is dependent on acceptance of the null hypothesis.

Experiment 4 attempted to overcome these problems by testing for further evidence of the operation of a nonlexical route by using word primes, as in the earlier studies.

\section{EXPERIMENT 4}

This experiment studied homophone priming effects as a function of the regularity of the target. If phonological information is only activated automatically via the lexicon, homophone priming should be found irrespective of the regularity of the target. This is because pimes processed lexically will always preactivate the same phonology as that of targets, regardless of whether or not targets conform to the spelling-to-sound rules of English. However, if nonlexical phonological activation occurs, priming should differ according to the regularity of targets. A nonlexical route would produce consistent phonological representations for regular primes and targets but inconsistent representations for all primes and exception targets. ${ }^{6}$ Even if lexical priming also occurs for both types of target, regular targets should benefit from having two sources of activation.

The same identity condition was not included in this experiment. In Experiments 1 and 2, there was more facilitation in this condition than in any other condition, demonstrating that the additional similarity between primes and targets incremented priming. However, since the present study was concerned with the means by 
which automatic phonological priming occurs, rather than the effects of different forms of information on word recognition, the same identity condition was superfluous.

\section{Method}

The subjects were 24 paid members of the Birkbeck College subject pool, 15 females and 9 males. All subjects had normal or corrected-to-normal vision and participated in a single experimental session of approximately $40 \mathrm{~min}$ duration. Although all the participants were naive to the purpose of the study, seven had previously taken part in either Experiment 1 or 2.

A target word pool of 84 words, between three and six letters long, was created. For half these words (the regular targets), the spelling-to-sound rules provided by Venezky (1970) generated their correct pronunciation; for the other (exception) words, the spelling-to-sound rules yielded incorrect pronunciations. Type of irregularity was not controlled. Word frequencies of targets varied between 0 and 3,284 per million in the Kučera and Francis (1967) norms, with the average word frequency being higher for exception targets than for regular targets ( 240 vs. 85 words/million). The difference in word frequency between the target types was unavoidable, given the restricted number of English homophones and the fact that exception words are often of very high frequency (e.g., WERE, BEEN, HAVE, etc.). However, to minimize the possibility of word frequency differentially affecting the priming conditions, homophone priming was tested within each target word type.

The regular and exception target word pools were divided into three groups of 14 , balanced for word length and frequency. For each target type, there were also three conditions, homophone, graphemic control, and unrelated control. These conditions matched those used in Experiment 1. Targets were presented in each condition by combining the three sets of targets within each word type with three groups of eight subjects using a Latin square design. The order of the conditions was randomized for each subject by computer.

Prior to the experimental trials, the exposure durations appropriate to each subject were found using the threshold procedure. During this phase, primes were words unrelated to targets.

\section{Results and Discussion}

The mean field duration was $40 \mathrm{msec}$, and there was a range between 30 and $45 \mathrm{msec}$ over subjects.

Table 4 shows the mean percent correct target identifications in each condition as a function of target type.

The data were analyzed using a mixed-design analysis of variance with one between-subjects factor (groups) and two within-subjects factors (target word type and conditions). The main effects of target word type

Table 4

Mean Percentage Correct Target Identification per Condition in Experiment 4

\begin{tabular}{llc}
\hline \multicolumn{2}{c}{ Condition } & $\begin{array}{c}\text { Percentage } \\
\text { Correct }\end{array}$ \\
\hline Homophone & Exception Word Target \\
Graphemic Control & shoot-CHUTE & \\
Unrelated Control & short-CHUTE & 63.83 \\
trail-CHUTE & 52.83 \\
Homophone Regular Word Target & 49.93 \\
Graphemic Control & stair-STARE & \\
Unrelated & stark-STARE & 56.60 \\
& quiet-STARE & 39.46 \\
\hline
\end{tabular}

and conditions were both significant $[F(1,21)=6.25$, $\mathrm{p}<.025$, and $\mathrm{F}(2,42)=24.29, \mathrm{p}<.001$, respectively $]$. However, the main effect of groups was not reliable $[F(2,21)=1.76, p>.05]$. None of the interactions between the groups, target word type, and conditions factors approached significance (all Fs $<1.0$ ).

The main effect of conditions was examined in more detail using the Newman-Keuls method. There was a reliable facilitation effect in the homophone condition relative to the graphemic and unrelated control conditions (both ps $<.01$ ). Target recognition was also facilitated in the graphemic control relative to the unrelated control treatment $(\mathrm{p}<.01)$.

These results show that phonological priming occurred between homophones both when targets were exception words and when targets were regular words. This effect occurred over and above a graphemic priming effect, indicated by the difference between the graphemic and unrelated controls.

In addition to these differences between the primetarget conditions, there was a significant main effect of word type, with exception targets being better recognized than regular targets. This was possibly due to the higher frequency of the exception targets. Crucially, however, there was no variation in the size of the phonological priming effect as a function of target word type. This demonstrates that neither target regularity nor target frequency differentially affected performance. However, it is interesting to note that priming effects on high frequency targets typically are smaller than priming effects on low frequency targets (e.g., Davelaar et al., 1978; Scarborough, Cortese, \& Scarborough, 1977; Scarborough, Gerard, \& Cortese, 1979). Thus, if anything, the word frequency effect should have operated to reduce phonological priming for exception targets. The phonological priming effect for these words cannot be attributed to a confounding of word frequency and target type. Further, the higher level of identification for exception words than regular words shows that regular word priming was not limited by a ceiling effect.

Pooling over subjects and target type, there were $21(3.1 \%)$ correct prime identifications out of 672 trials in the homophone condition, $14(2.2 \%)$ in the graphemic control, and $4(.6 \%)$ in the unrelated control. On no trials when primes were reported were targets also correctly reported, and no subject reported seeing lowercase letters. Since prime identification was minimal, we can again conclude that automatic priming took place.

Since homophone priming was of the same magnitude for exception and regular targets here, it supports the proposal that primes gain automatic access to phonology via a lexical route.

\section{GENERAL DISCUSSION}

Four experiments examined the automatic access of phonological information in visual word recognition. A priming technique was used that prevented the inten- 
tional usage of prime information, since correct prime identifications were minimal and the presence of lowercase prime letters was not reported. Under such conditions, priming is due to the automatic activation of target representations by primes.

Experiments 1 and 2 showed significant facilitation of target identification when primes and targets were homophones, compared with both graphemic and unrelated control conditions. Experiment 3 showed no such priming effect when primes were nonwords that were homophonic to targets. It was argued from this that automatic phonological priming only occurs when primes can gain lexical (whole-word) access to phonology. Experiment 4 provided more evidence on this point. It showed a similar homophone priming effect for both regular and exception target words. If a nonlexical GPC process had mediated phonological priming, regular targets should have been primed more than exception targets, since the exception targets' phonology can only be correctly accessed via the lexicon. Thus, these experiments show that phonological information is automatically activated in visual word recognition, and that this occurs by means of a lexical route.

It remains to specify the locus of the facilitation effect. A recent approach to lexical organization is one in which the lexicon is subdivided into functionally independent orthographic, phonological, and semantic representations (e.g., Allport \& Funnell, 1981; Morton \& Patterson, 1980). A primary motivation for these subdivisions is the pattern of dissociable abilities found when reading breaks down after neurological damage (e.g., Schwartz, Marin, \& Saffran, 1979). Facilitated target identification could arise from priming one or more of these representations. For instance, primes could not only activate the phonological addresses of targets, but also their orthographic and/or semantic addresses by a feedback process from the phonological lexicon (see, respectively, McClelland \& Rumelhart, 1981; Coltheart, Masterson, Byng, Prior, \& Riddoch, Note 1). Interestingly, by far the majority of errors that subjects made when misidentifying targets were graphemically, rather than phonologically or semantically, related to targets. ${ }^{7}$ This suggests that subjects based their responses on the activation of orthographic information. One parsimonious explanation of both the error responses and the phonological priming effect is that errors stem from the failure to fully activate the orthographic lexicon, and that this process is facilitated when phonological information from the prime preactivates the target's orthographic address.

The present lack of evidence for nonlexical access to phonology may be due to several reasons. For example, nonlexical access may simply be too slow to affect performance under the present circumstances (Coltheart, 1978, 1980), or it may be an intentional, strategic process (Carr et al., 1978; Davelaar et al., 1978; Hawkins et al., 1976). However, a more radical alterna- tive is that an independent, nonlexical route to phonology does not exist (Glushko, 1979; Kay \& Marcel, 1981; Marcel, 1980). According to this notion, all visually presented letter strings are processed lexically. The only difference between words and nonwords is that words have stored representations appropriate to the whole letter string.

There are two main pieces of evidence for this view to explain. One is how readers pronounce nonwords. This can be accounted for if communication between orthographic and phonological representations in the lexicon operates on the basis of multiple orthographic units, varying in size. Each of these units will have its own phonological representation associated with it. When a letter string is presented, there is parallel activation of all orthographic units. The smaller phonological units that become activated can be combined to generate the pronunciation of any unfamiliar letter string (Marcel, 1980).

The failure to find a pseudohomophone priming effect in Experiment 3 demonstrates that such segmentation was ineffective here (see Evett \& Humphreys, 1981, Experiment 2) and that automatic lexical access to phonology operated at the whole-word level. To explain this, we must assume either that segmentation is slower than whole-word communication or that it is an intentional process.

The second piece of evidence to explain is the regularity effect in word naming. However, recent work suggests that it is the phonological consistency of words with their orthographic neighbors (i.e., words with similar orthographies), rather than their regularity, that primarily determines both naming (Glushko, 1979) and lexical decision performance (Bauer \& Stanovich, 1980). These results fit with the lexical route account. For instance, a consistent word (e.g., WADE) may activate not only its own orthographic representation but also those of orthographically similar words (MADE, SHADE, etc.). Any associated phonological representations that become activated will match that of the stimulus. In contrast, an inconsistent word (WAVE) will activate neighbors with different pronunciations (HAVE). This could produce slower naming times because of competition between different pronunciations (Marcel, 1980). Alternatively, this could occur because activated phonological representations could decrease activation in any unrelated phonological representations, thereby leading to mutual inhibition between inconsistent neighbors (McClelland \& Rumelhart, 1981). The finding of similar effects with nonwords (Glushko, 1979) reinforces the view that all letter strings are subject to the same processing routes.

It seems valid to conclude from this that, on the grounds of parsimony at least, there is no requirement for current models of word processing to continue to posit two functionally independent routes to phonology; the same lexically mediated processes are applied to all 
letter strings. The present experiments demonstrate the rapid, automatic operation of this lexical route at the whole-word level. The effects of the phonological information so accessed would also be expected in other tasks requiring more explicit use of phonology. There seems no need in these cases to assume that phonological information is accessed nonlexically.

\section{REFERENCE NOTES}

1. Coltheart, M., Masterson, J., Byng, S., Prior, M., \& Riddoch, J. Surface dyslexia. Manuscript in preparation, 1981.

2. Meyer, D. E., \& Gutschera, K. D. Orthographic versus phonemic processing of printed words. Paper presented at the annual meeting of the Psychonomic Society, Denver, November 1975.

\section{REFERENCES}

Allport, D. A. On knowing the meaning of words we are unable to report: The effects of visual masking. In S. Dornic (Ed.), Attention and performance VI. Potomac, Md: Erlbaum, 1977.

Allpont, D. A., \& Funnell, E. Components of the mental lexicon. Philosophical Transactions of the Royal Society, 1981.

Baron, J., \& Strawson, C. Use of orthographic and word specific knowledge in reading words aloud. Journal of Experimental Psychology: Human Perception and Performance, 1976, 2, 386-393.

Bayen, D. W., \& Stanovich, K. E. Lexical access and the spelling-to-sound regularity effect. Memory \& Cognition, 1980, $8,424-432$.

Carr, T. H., Davidson, B. J., \& Hawkins, H. L. Perceptual flexibility in word recognition: Strategies affect orthographic computation but not lexical access. Journal of Experimental Psychology: Human Perception and Performance, 1978, 4, 674-690.

Clark, H. H. The language-as-fixed-effect fallacy: A critique of language statistics in psychological research. Journal of Verbal Learning and Verbal Behavior, 1973, 12, 335-359.

Coltheart, M. Lexical access in simple reading tasks. In G. Underwood (Ed.), Strategies of information processing. London: Academic Press, 1978.

Colthe ART, M. Reading, phonological recoding, and deep dyslexia. In M. Coltheart, K. Patterson, \& J. C. Marshall (Eds.), Deep dyslexia. London: Routledge \& Kegan Paul, 1980.

Colthenzt, M., Jonaseon, J. T., Davelaar, E., Begner, D. Access to the internal lexicon. In S. Dornic (Ed.), Attention and performance VI. Potomac, Md: Erlbaum, 1977.

Davelaar, E., Coltheart, M., Besner, D., \& Jonagson, J. Phonological recoding and lexical access. Memory \& Cognition, $1978,6,391-402$.

Ell18, A. W., \& Marshall, J. C. Semantic errots or statistical flukes? A note on Allport's "On knowing the meaning of words we are unable to report." Quarterly Journal of Experimental Psychology, 1978, 30, 569-575.

EvetT, L. J., \& HumphreY8, G. W. The use of abstract graphemic information in lexical access. Quarterly Journal of Experimental Psychology, 1981, 33A, 325-350.

Forste R, K. I. Accessing the internal lexicon. In R. J. Wales \& E. C. T. Walker (Eds.), New approaches to language mechanisms. Amsterdam: North-Holland, 1976.

Fowren, C. A., Wolmond, G., Slade, R., \& Tassinary, L. Lexical access with and without awareness. Journal of Experimental Psychology: General, 1981, 110, 341-362.

Guusrкo, R. The organization and activation of orthographic knowledge in reading aloud. Journal of Experimental Psychology: Human Perception and Performance, 1979, 5, 674. 691.
Gough, P. B., \& Cosky, M. J. One second of reading again. In N. J. Castellan, D. B. Pisoni, \& G. R. Potts (Eds.), Cognitive theory (Vol. 2). Hillsdale, N.J: Erlbaum, 1977.

Hawkins, H. L., Reicher, G. M., Rogers, M., \& Peterson, L. Flexible coding in word recognition. Journal of Experimental Psychology: Human Perception and Performance, 1976. 2, 380-385.

Hillinaer, M. L. Priming effects with phonemically similar words: The encoding-bias hypothesis reconsidered. Memory a Cognition, 1980, 8, 115-123.

HUMPhREYs, G. W. Direct vs. indirect tasks of the information available from masked displays: What visual masking does and does not prevent. British Journal of Psychology, 1981, 72, 323-330.

Johnston, J. C., \& McClelland, J. L. Experimental tests of a hierarchical model of word identification. Journal of Verbal Learning and Verbal Behavior, 1980, 19, 503-535.

KAY, J., \& MARCEL, A. J. One process, not two, in reading aloud: Lexical analogies do the work of nonlexical rules. Quarterly Journal of Experimental Psychology, 1981, 33A. 397-414.

Kú̇era, H., \& Francts, W. N. Computational analysis of present-day American English. Providence, R.I: Brown University Press, 1967.

LogAN, G. D. Attention and automaticity in Stroop and priming tasks: Theory and data. Cognitive Psychology, 1980, 12, 523. 553.

MARCEL, A. J. Surface dyslexia and beginning reading: A revised hypothesis of the pronunciation of print and its impairments. In M. Coltheart, K. Patterson, \&. C. Marshall (Eds.), Deep dyslexia. London: Routledge \& Kegan Paul, 1980.

Marcel, A. J. Conscious and unconscious perception: Visual masking, word recognition and an approach to consciousness. Cognitive Psychology, in press.

McClelland, J. L., \& Rumelhart, D. E. An interactive activation model of context effects in letter perception: Part 1. An account of basic findings. Psychological Review, 1981, 5, 375-407.

McLean, J. P., \& Shulman, G. L. On the construction and maintenance of expectancies. Quarterly Journal of Experimental Psychology, 1978, 30, 441-454.

Meyer, D. E., Schvaneveldt, R. W., \& Ruddy, M. G. Functions of graphemic and phonemic codes in visual wordrecognition. Memory \& Cognition, 1974, 2, 309-321.

Michaels, C. F., \& Turvey, M. T. Central sources of visual masking: Indexing structures supporting seeing at a single, brief glance. Psychological Research, 1979, 11, 1-61.

Morton, J., \& PAtTe rson, K. A new attempt at an interpretation, or, an attempt at a new interpretation. In M. Coltheart, K. Patterson, \& J. C. Marshall (Eds.), Deep dyslexia. London: Routledge \& Kegan Paul, 1980.

NeELy, J. H. Semantic priming and retrieval from lexical memory: The roles of inhibitionless spreading activation and limitedcapacity attention. Journal of Experimental Psychology: General, 1977, 106, 226-254.

Posner, M. I. Chronometric explorations of mind. Hillsdale, N.J: Erlbaum, 1978.

Posner, M. I., \& Snyder, C. R. R. Attention and cognitive control. In R. L. Solso (Ed.), Information processing and cognition: The Loyola Symposium. Hillsdale, N.J: Erlbaum, 1975.

RAYNER, K. The control of eye movements in reading: Eye guidance and visual integration. In P. A. Kolers, M. E. Wrolstad, \& H. Bouma (Eds.), The processing of visible language 1. New York: Plenum Press, 1979.

Rubenstein, H., Lew18, S. S., \& Rubenotein, M. A. Evidence for phonemic recoding in visual word recognition. Journal of Verbal Learning and Verbal Behavior, 1971, 10, 645-658.

Scarborough, D. L., Cortese, C., \& Scanmorovah, H. S. Frequency and repetition effects in lexical memory. Journal of Experimental Psychology: Human Perception and Performance, 1977, 3, 1-17. 
Scarborough, D. L., Gerard, L., \& Cortese, C. Accessing lexical memory: The transfer of word repetition effects across task and modality. Memory \& Cognition, 1979, 7, 3-12.

Schwartz, M. F., Marin, O. S. M., \& Saffran, E. M. Dissociations of language function in dementia: $A$ case study. Brain and Language, 1979, 7, 277-306.

Shulman, H. G., Hornak, R., \& Sanders, E. The effects of graphemic, phonetic, and semantic relationships on access to lexical structures. Memory \& Cognition, 1978, 6, 115-123.

Stanovich, K. E., \& BAuER, D. W. Experiments on the spellingto-sound regularity effect in word recognition. Memory \& Cognition, 1978, 6, 410-415.

Tanenhaus, M. K., Flanigan, H. P., \& Seidenberg, M. S. Orthographic and phonological activation in auditory and visual word recognition. Memory \& Cognition, 1980, 8, 513-520.

TAYLOR, D. E. Automatic processes in word recognition. Unpublished doctoral dissertation. Bristol University, 1981.

TAYLOR, G. A., \& CHABOT, R. J. Differential backward masking of words and letters by masks of varying orthographic structure. Memory \& Cognition, 1978, 6, 629-635.

TURveY, M. T. Visual processing of short-term memory. In W. K. Estes (Ed.), Handbook of learning and cognitive processes (Vol. 5). Hillsdale, N.J: Erlbaum, 1978.

VEnEzKY, R. L. The structure of English orthography. The Hague: Mouton Press, 1970.

Wike, E. L., \& Church, J. D. Comments on Clark's "The language-as-fixed-effect fallacy." Journal of Verbal Learning and Verbal Behavior, 1976, 15, 249-255.

Williams, P. C., \& Parkin, A. J. On knowing the meaning of words we are unable to report: Confirmation of a guessing explanation. Quarterly Journal of Experimental Psychology, $1980,32,101-108$.

\section{NOTES}

1. A further, more remote possibility is that priming was confounded by repeating stimuli, which occurred as both primes and targets across trials. However, the design used by Evett and Humphreys (1981) was an exact replication of the study of Meyer et al. (1974), who obtained phonological priming with primes that were not masked. It therefore seems likely that the lack of phonological priming in Evett and Humphreys is due to primes being masked to prevent their intentional usage, and not due to repetitions.

2. For all analyses in the paper, the results are only generalized statistically over subjects. This is because the stimuli in each experiment were restricted and did not form a random sample of words (cf. Clark, 1973).
Nevertheless, the results were always replicated over different stimulus pools, which should allow valid generalizations to be made over stimuli (Wike \& Church, 1976).

3. Subjects were usually both reluctant and unable to produce two responses to displays, and they often reported that their single responses were made with little confidence.

4. There was an average of $44.6 \%$ common letters between primes and targets in the graphemic control in Experiment 3 and an average $42.7 \%$ and $44.2 \%$ in the analogous conditions in Experiments 1 and 2. Also, although there were no common letters between the stimuli in the unrelated control of Experiment 3 , there was an average of $.9 \%$ and $2.4 \%$ in the unrelated control conditions in Experiments 1 and 2. Thus, there was an average $44.6 \%$ difference between the controls in Experiment 3 and an average $41.8 \%$ difference in both Experiments 1 and 2 . In Experiment 4, there was an average difference of $43.0 \%$ of common letters between the controls, and a facilitation effect of $4.78 \%$ in the graphemic control condition.

5. One way to operationally define nonwords as being homophonous with words is to ensure they produce a pseudohomophone effect in a lexical decision task. The pseudohomophone effect is the slower rejection of letter strings as not being words when they are phonologically identical to words (e.g., BRANE) than when they have the same level of orthographic regularity but are not phonologically identical to a word (BRAME). This is presumed to occur because pseudohomophones can be segmented to generate the phonological representations of the homophonous words. Their rejection is delayed because they activate the stored phonological addresses of the words. The pseudohomophones used in Experiment 3 produced this effect ( $717 \mathrm{msec}$ vs. $688 \mathrm{msec}$ for the pseudohomophones and their orthographically matched nonword controls; $p<.05$ ).

6 . For the regular targets, 40 of 42 of the primes in the homophone condition were also regular ("board" and "fete" being the exceptions). This should have enabled nonlexical phonological priming to operate for the great majority of regular targets.

7. A detailed analysis of the errors in the homophone condition of Experiment 4 was conducted. Errors were grouped into three categories that were not necessarily mutually exclusive. They were classified as graphemic errors if they contained a majority of target letters, phonological if they contained a majority of target phonemes, and semantic if they were semantically related. Pooling over subjects, $74.5 \%$ of the errors were of the graphemic variety, $27.6 \%$ phonological, and $5.2 \%$ semantic. All the phonological errors were also graphemically related to targets (LACKS-TACKS; ROUGH-TOUGH), but $46.9 \%$ of the graphemic errors were neither phonologically nor semantically related (HEAR-WEAR; HEARD-THREAD).

Appendix A

Materials for Experiment 1

\begin{tabular}{lcccc}
\hline Target & Same Identity & Homophone & Graphemic Control & Unrelated Control \\
\hline DAYS & days & daze & dare & fury \\
PAIL & pail & pale & pack & torn \\
MAIL & mail & male & mall & hurl \\
PAIN & pain & pane & pant & duck \\
SORE & sore & soar & soup & fame \\
ROSE & rose & rows & rods & feel \\
LAIN & lain & lane & land & dead \\
LOOT & loot & lute & late & kind \\
HERE & here & hear & help & tale \\
POOR & poor & pore & port & groin \\
GROWN & grown & groan & self & thic \\
SEIZE & seize & seas & park & lool \\
PIQUE & pique & peak & final & story
\end{tabular}




\begin{tabular}{|c|c|c|c|c|}
\hline Target & Same Identity & Homophone & Graphemic Control & Unrelated Control \\
\hline ROOT & root & route & round & index \\
\hline SORT & sort & sought & socket & napkin \\
\hline RUFF & ruff & rough & reach & serve \\
\hline DYED & dyed & died & deed & junk \\
\hline VALE & vale & veil & veal & cosy \\
\hline BOAR & boar & bore & bone & gift \\
\hline CHUTE & chute & shoot & shock & trail \\
\hline FLAIR & flair & flare & flask & cheek \\
\hline LONE & lone & loan & loop & crop \\
\hline SOLE & sole & soul & sock & tack \\
\hline BLEW & blew & blue & blot & goat \\
\hline MOAT & moat & mote & moth & fern \\
\hline BREAK & break & brake & brick & twist \\
\hline SIGHS & sighs & size & sill & apex \\
\hline CLAUSE & clause & claws & clamp & rotor \\
\hline WHICH & which & witch & winch & plant \\
\hline MIGHT & might & mite & mist & weep \\
\hline RAZE & raze & raise & rally & mouse \\
\hline CREWS & crews & cruise & crisis & nobody \\
\hline SLAY & slay & sleigh & slight & bitter \\
\hline SINE & sine & sign & silk & pray \\
\hline STAIR & stair & stare & stark & guild \\
\hline MARE & mare & mayor & major & long \\
\hline VEIN & vein & vane & vine & dump \\
\hline STAKE & stake & steak & steal & plumb \\
\hline GREAT & great & grate & grant & blind \\
\hline BALE & bale & bail & bath & fist \\
\hline GAIT & gait & gate & gall & lump \\
\hline SUITE & suite & sweet & sheet & angry \\
\hline YOLK & yolk & yoke & yoga & gash \\
\hline FOWL & fowl & foul & foil & grip \\
\hline SWAYED & swayed & suede & stead & timid \\
\hline REIGN & reign & rain & rail & damp \\
\hline WOULD & would & wood & wore & desk \\
\hline LEASED & leased & least & leash & crook \\
\hline BUILD & build & billed & boiled & coarse \\
\hline CITE & cite & sight & giant & radar \\
\hline FORT & fort & fought & follow & cattle \\
\hline HIGHER & higher & hire & hill & boat \\
\hline COURT & court & caught & cavort & parcel \\
\hline TIED & tied & tide & till & pull \\
\hline FAIR & fair & fare & farm & note \\
\hline THROWN & thrown & throne & throat & advice \\
\hline MOAN & moan & mown & moon & nose \\
\hline HAIR & hair & hare & hall & food \\
\hline PAIR & pair & pear & pier & lobe \\
\hline MADE & made & maid & mark & ship \\
\hline WRITE & write & right & ridge & chase \\
\hline RODE & rode & road & raid & halt \\
\hline SAIL & sail & sale & salt & bond \\
\hline BRIDAL & bridal & bridle & bridge & energy \\
\hline SOARED & soared & sword & sewed & digit \\
\hline PAUSE & pause & paws & paid & bill \\
\hline FLOWER & flower & flour & flout & icing \\
\hline MANNER & manner & manor & manic & idiot \\
\hline TOAD & toad & towed & today & quite \\
\hline WELD & weld & welled & welter & gambit \\
\hline BARE & bare & bear & bean & pond \\
\hline
\end{tabular}

Appendix B

Materials for Experiment 2

\begin{tabular}{clccc}
\hline Target & $\begin{array}{c}\text { Same } \\
\text { Identity }\end{array}$ & Homophone & $\begin{array}{c}\text { Graphemic Nonword } \\
\text { Control }\end{array}$ & $\begin{array}{c}\text { Unrelated Word } \\
\text { Control }\end{array}$ \\
\hline PAIL & pail & pale & paln & torn \\
MAIL & mail & male & malo & hurt \\
POOR & poor & pore & porm & tick \\
ROSE & rose & rows & rons & fate
\end{tabular}




\begin{tabular}{|c|c|c|c|c|}
\hline Target & $\begin{array}{c}\text { Same } \\
\text { Identity }\end{array}$ & Pseudohomophone & $\begin{array}{c}\text { Graphemic Nonword } \\
\text { Control }\end{array}$ & $\begin{array}{c}\begin{array}{c}\text { Unrelated Nonword } \\
\text { Control }\end{array} \\
\end{array}$ \\
\hline SORE & sore & soar & soir & bulk \\
\hline LOOT & loot & lute & lote & dred \\
\hline YOLK & yolk & yoke & yoki & gash \\
\hline SOLE & sole & soul & soal & tack \\
\hline GROWN & grown & groan & groon & ethic \\
\hline CHUTE & chute & shoot & shoat & trail \\
\hline PIECE & piece & peace & perce & slant \\
\hline BUILD & build & billed & bilked & sought \\
\hline RUFF & ruff & rough & roath & serve \\
\hline BORED & bored & board & bourd & match \\
\hline SEIZE & seize & seas & seir & tool \\
\hline ROUTE & route & root & roat & wind \\
\hline SOARED & soared & sword & snord & digit \\
\hline PRAISE & praise & prays & prags & teeth \\
\hline LAIN & lain & lane & lano & feel \\
\hline PAIR & pair & pear & poar & lobe \\
\hline HAIR & hair & hare & harn & food \\
\hline PAIN & pain & pane & pand & duck \\
\hline LONE & lone & loan & lorn & crop \\
\hline BOAR & boar & bore & borm & gift \\
\hline MITE & mite & might & mith & grip \\
\hline SAIL & sail & sale & salm & band \\
\hline BREAD & bread & bred & brod & last \\
\hline FLAIR & flair & flare & flarn & check \\
\hline BREAK & break & brake & breka & twist \\
\hline BURY & bury & berry & borny & grant \\
\hline RAZE & raze & raise & rance & mouse \\
\hline MODE & mode & mowed & mobed & rally \\
\hline PIQUE & pique & peak & pemt & lord \\
\hline TACKS & tacks & $\operatorname{tax}$ & tad & pig \\
\hline LEASED & leased & least & leask & crook \\
\hline FLOWER & flower & flour & floir & icing \\
\hline DYED & dyed & died & daed & junk \\
\hline RODE & rode & road & rond & halt \\
\hline HERE & here & hear & heor & kind \\
\hline VEIN & vein & vane & vone & dump \\
\hline BLEW & blew & blue & blie & goat \\
\hline FATE & fate & fete & fote & ploy \\
\hline MOAT & moat & mote & motu & fern \\
\hline TALE & tale & tail & taol & ship \\
\hline PASTE & paste & paced & panet & giant \\
\hline STAIR & stair & stare & starn & guild \\
\hline SUITE & suite & sweet & soret & angry \\
\hline COURT & court & caught & caurot & blithe \\
\hline SLAY & slay & sleigh & slutch & bitter \\
\hline SUEDE & suede & swayed & swoyed & parked \\
\hline SIGHS & sighs & size & sion & apex \\
\hline PAUSE & pause & paws & pams & ball \\
\hline MANNER & manner & manor & manur & idiot \\
\hline TOWED & towed & toad & tood & quit \\
\hline VALE & vale & veil & veol & cosy \\
\hline TIED & tied & tide & tike & pill \\
\hline DAYS & days & daze & dape & fury \\
\hline FAIR & fair & fare & farn & note \\
\hline SEWN & sewn & sown & suwn & lump \\
\hline MOAN & moan & mown & moin & pick \\
\hline BAIL & bail & bale & barl & fast \\
\hline BARE & bare & bear & biar & land \\
\hline STAKE & stake & steak & stoak & plumb \\
\hline PLAIN & plain & plane & plang & final \\
\hline WRITE & write & right & riget & count \\
\hline MARE & mare & mayor & mager & long \\
\hline FIND & find & fined & finod & story \\
\hline WELD & weld & welled & welted & gambit \\
\hline REIGN & reign & rain & roin & deal \\
\hline CREWS & crews & cruise & croise & winch \\
\hline HIGHER & higher & hire & hier & plus \\
\hline CLAUSE & clause & claws & clars & rotor \\
\hline
\end{tabular}


Appendix C

Materials for Experiment 3

\begin{tabular}{|c|c|c|c|c|}
\hline Target & $\begin{array}{c}\text { Same } \\
\text { Identity }\end{array}$ & Pseudohomophone & $\begin{array}{c}\text { Graphemic Nonword } \\
\text { Control }\end{array}$ & $\begin{array}{l}\text { Unrelated Nonword } \\
\text { Control }\end{array}$ \\
\hline BALL. & ball & borl & boal & seaf \\
\hline BLUE & blue & bloo & blad & dift \\
\hline BOAT & boat & bote & bots & merp \\
\hline BOIL & boil & boyl & boll & dard \\
\hline BORN & born & bawn & blen & mexe \\
\hline BOWL & bowl & boal & bool & prad \\
\hline BRAIN & brain & brane & brant & pevel \\
\hline BREAK & break & braik & brank & ploit \\
\hline BROAD & broad & brawd & brend & plesk \\
\hline BROOD & brood & brude & breds & liske \\
\hline BRUISE & bruise & brooze & breale & chooth \\
\hline CABLE & cable & kabel & vabel & flirk \\
\hline CALL & call & korl & poil & bift \\
\hline CALM & calm & karm & raim & dind \\
\hline CARS & cars & karz & vart & voit \\
\hline CANDLE & candle & kandel & fandel & thourp \\
\hline CAUSE & cause & corze & chole & bloot \\
\hline CHEWS & chews & chuse & chash & fronk \\
\hline CHOIR & choir & kwyre & keare & blant \\
\hline CIRCLE & circle & sirkul & pirail & lupont \\
\hline CLAIM & claim & klame & plame & brust \\
\hline CLAW & claw & klor & blet & derm \\
\hline CLUE & clue & klew & blan & frag \\
\hline COAL & coal & kole & tolk & dest \\
\hline CORN & corn & kawn & fean & sult \\
\hline CUFF & cuff & kuph & wuth & bion \\
\hline DIAL & dial & dile & dild & resh \\
\hline DOOR & door & dawe & daip & pash \\
\hline DRAW & draw & dror & drep & noth \\
\hline DREW & drew & droo & diof & ston \\
\hline EFFECT & effect & ephect & eshect & torish \\
\hline FALL & fall & forl & firl & curf \\
\hline FAWN & fawn & forn & flun & seab \\
\hline FLEW & flew & floo & flam & barp \\
\hline FOIST & foist & foyst & foost & shafe \\
\hline FORM & form & fawm & feam & tupe \\
\hline FOUR & four & phaw & thep & tath \\
\hline GHOST & ghost & goast & golst & drick \\
\hline HALL & hall & horl & hoil & posk \\
\hline HAWK & hawk & hork & heek & nump \\
\hline KALE & kale & cail & darl & houb \\
\hline KNEES & knees & nease & nerth & moiph \\
\hline KNIFE & knife & niphe & nishe & plaim \\
\hline LAWN & lawn & lorn & lirn & rerd \\
\hline LEARN & learn & lurne & loine & domud \\
\hline LORD & lord & lawd & lind & saft \\
\hline MAUL & maul & morl & mool & rern \\
\hline MILE & mille & mial & mirl & durm \\
\hline PAUSE & pause & porze & pirde & holck \\
\hline PHASE & phase & fayze & daipe & trund \\
\hline QUEEN & queen & kwene & frene & bramb \\
\hline QUIET & quiet & kwiet & driet & shoup \\
\hline QUITE & quite & kwyte & saite & cresp \\
\hline QUOTE & quote & kwoat & droit & valad \\
\hline RAKE & rake & raik & rark & disp \\
\hline RATE & rate & rait & ralt & sisk \\
\hline ROOF & roof & rufe & rurt & dism \\
\hline SALE & sale & sayl & sarl & toop \\
\hline SANE & sane & sain & sarn & jusk \\
\hline SCORE & score & skawe & shide & flink \\
\hline SCREW & screw & skroo & shrid & thoul \\
\hline SHORT & short & shawt & shait & prind \\
\hline SMALL & small & smorl & smoul & thoke \\
\hline SORT & sort & sawt & sant & chep \\
\hline STALK & stalk & stawl & stask & hoobe \\
\hline STYLE & style & stial & starl & choip \\
\hline SURE & sure & shor & skir & pank \\
\hline
\end{tabular}




\begin{tabular}{llccc} 
Target & $\begin{array}{c}\text { Same } \\
\text { Identity }\end{array}$ & Pseudohomophone & $\begin{array}{c}\text { Graphemic Nonword } \\
\text { Control }\end{array}$ & $\begin{array}{c}\text { Unrelated Nonword } \\
\text { Control }\end{array}$ \\
\hline TALK & talk & tork & tink & lurp \\
THREW & threw & throo & thrad & maind \\
TILE & tile & tial & tirl & frag \\
TOAD & toad & tode & tods & leck \\
TOIL & toil & toyl & tobe & nath \\
TRADE & trade & traid & trand & gloin \\
TRIAL & trial & tryel & trool & kwobe \\
VASE & vase & varz & vald & chot \\
WALL & wall & worl & woil & sime \\
WAYS & ways & waze & waip & holl \\
WEEP & weep & weap & werp & nosk \\
WOMEN & women & wimen & wamen & haith \\
WORRY & worry & wurie & warch & nanth \\
\hline
\end{tabular}

Appendix D

Materials for Experiment 4

\begin{tabular}{|c|c|c|c|c|c|c|c|}
\hline $\begin{array}{l}\text { Regular } \\
\text { Target }\end{array}$ & Homophone & $\begin{array}{c}\text { Graphemic } \\
\text { Control }\end{array}$ & $\begin{array}{l}\text { Unrelated } \\
\text { Control }\end{array}$ & $\begin{array}{l}\text { Exception } \\
\text { Target }\end{array}$ & Homophone & $\begin{array}{c}\text { Graphemic } \\
\text { Control }\end{array}$ & $\begin{array}{c}\text { Unrelated } \\
\text { Control }\end{array}$ \\
\hline DAYS & daze & dare & note & BEAR & bare & bade & long \\
\hline PAIL & pale & pack & drop & WERE & ware & wade & soup \\
\hline MAIL & male & mall & pick & GREAT & grate & grade & angry \\
\hline SORE & soar & soap & rack & BEEN & bean & bead & mist \\
\hline ROSE & rows & Iods & seal & TOUR & tore & tote & jean \\
\hline FLAIR & flare & flame & idiot & SOME & sum & sun & ark \\
\hline CAUGHT & court & count & icing & STEAK & stake & stare & plumb \\
\hline LACKS & lax & $\mathrm{lad}$ & pit & BOWLED & bold & born & seed \\
\hline STARE & stair & stark & quiet & BREAK & brake & brail & winch \\
\hline HIGHER & hire & hide & plus & BUILD & billed & boiled & sought \\
\hline WITCH & which & winch & prank & DOUGH & doe & $\operatorname{dot}$ & ram \\
\hline MANOR & manner & manger & nobody & EARN & urn & arm & $\cot$ \\
\hline TACKS & $\operatorname{tax}$ & tap & ink & MAYOR & mare & made & desk \\
\hline FATE & fete & fame & tops & MOWN & moan & moat & gash \\
\hline PAUSE & paws & paid & bill & PEAR & pair & poor & silk \\
\hline LAIN & lane & land & firm & CASTE & cast & cost & grip \\
\hline SIGHS & size & sire & heal & SOUL & sole & sock & fern \\
\hline BORED & board & boned & check & CHUTE & shoot & short & trial \\
\hline PASTE & paced & paged & shock & THROWN & throne & throat & picked \\
\hline SAIL & sale & sane & fist & QUAY & key & $\operatorname{coy}$ & bat \\
\hline VANE & vein & vine & keep & SIGN & sine & sink & lump \\
\hline FLOUR & flower & flowed & dinghy & SWORD & soared & soiled & runner \\
\hline PLANE & plain & plant & meaty & HEIR & air & aid & tip \\
\hline SIDE & sighed & singer & advice & SUEDE & swayed & stayed & danger \\
\hline FINED & find & fins & halt & WAR & wore & wire & ship \\
\hline RIGHT & write & white & cheer & GROWN & groan & groin & plant \\
\hline RAIN & reign & realm & cower & BURY & berry & belly & final \\
\hline WELLED & weld & welk & back & TOLLED & told & tale & gash \\
\hline TOWED & toad & teed & rest & HEARD & herd & hard & crop \\
\hline SIGHT & cite & coat & fear & SHOE & shoo & show & weep \\
\hline HEAR & here & heed & bolt & HEY & hay & hoy & lag \\
\hline BRIDAL & bridle & bridge & touch & SUITE & sweet & sweat & again \\
\hline WAIL & whale & wheel & bleak & SEWN & sown & sawn & $\cos y$ \\
\hline MADE & maid & maim & rear & FOUR & fore & fork & pull \\
\hline VALE & veil & veal & hand & $\mathrm{BROOCH}$ & broach & breach & twist \\
\hline DEW & due & $\operatorname{dog}$ & lip & ALE & ail & aim & den \\
\hline BLEW & blue & bled & idol & SUIT & soot & sort & wail \\
\hline CRUISE & crews & cries & gears & FAYRE & fare & fore & tick \\
\hline YOKE & yolk & yoga & body & WOOD & would & world & teally \\
\hline PACKED & pact & pace & fend & BUOY & boy & bay & fad \\
\hline ROUGH & ruff & riff & $\operatorname{limp}$ & BOUGH & bow & bog & $\mathrm{rag}$ \\
\hline CLAWS & clause & claims & leave & THYME & time & tame & mark \\
\hline
\end{tabular}

Note-See text for a description of how the items were combined for each experiment. 